\title{
Author Correction: Treatment of Intracranial Aneurysms with the Pipeline Embolization Device Only: a Single Center Experience
}

Volker Maus, $\mathrm{MD}^{1}$, Anastasios Mpotsaris, $\mathrm{MD}^{1}$, Jan Borggrefe, $\mathrm{MD}^{1}$, Nuran Abdullayev, $\mathrm{MD}^{1}$, Thomas Liebig, $\mathrm{MD}^{2}$, Franziska Dorn, $\mathrm{MD}^{3}$, Pantelis Stavrinou, $\mathrm{MD}^{4}$, De-Hua Chang, $\mathrm{MD}^{1}$, Christoph Kabbasch, $\mathrm{MD}^{1}$

${ }^{1}$ Department of Diagnostic and Interventional Neuroradiology, University Hospital Cologne, Cologne, Germany

${ }^{2}$ Department of Neuroradiology, Charité, Berlin, Germany

${ }^{3}$ Department of Neuroradiology, University Hospital Munich (LMU), Munich, Germany

${ }^{4}$ Department of Neurosurgery, University Hospital Cologne, Cologne, Germany

Correction to: Neurointervention https://doi.org/10.5469/neuroint.2018.13.1.32, published on March, 2018, Neurointervention 2018;13:32-40

The originally published version of this Article contained an error in the author list: the last and first names of all authors are inverted.

Before correction: Maus Volker, MD', Mpotsaris Anastasios, MD', Borggrefe Jan, MD', Abdullayev Nuran, MD', Liebig Thomas,

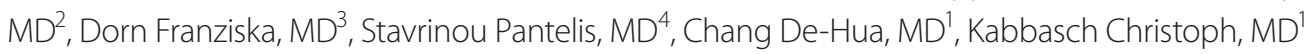

After correction: Volker Maus, MD'1, Anastasios Mpotsaris, MD', Jan Borggrefe, MD', Nuran Abdullayev, MD', Thomas Liebig, MD², Franziska Dorn, MD³, Pantelis Stavrinou, MD', De-Hua Chang, MD', Christoph Kabbasch, MD 